\title{
CONTROL OPTIMISATION OF THE NEW DRIVE OF SMALL DIAMETER KNITTING MACHINES
}

\author{
Josef Skřivánek ${ }^{1}$ Martin Bílek ${ }^{1}$ and Michal Kašpárek ${ }^{2}$ \\ ${ }^{1}$ Technická univerzita v Liberci, Fakulta strojní, Katedra textilních a jednoúčelových strojů, Studentská 2, 46117 Liberec, Česká republika, \\ josef.skrivanek@tul.cz, martin.bilek@tul.cz \\ ${ }^{2}$ Technická univerzita v Liberci, Fakulta strojní, Katedra aplikované kybernetiky, Studentská 2, 46117 Liberec, Česká republika, \\ michal.kasparek@tul.cz
}

\begin{abstract}
:
The article is concerned with the issues of the drive of small diameter knitting machines. In connection to the proposal of optimum structure of the driving systems of the machine, there have been analysed the possibilities of precisely controlled servo drives. An optimised structure of the drives allows for the utilisation of precisely defined position and velocity functions. There is applied here the function of a polynomial of 7th degree, proposed for impact-free course of the acceleration, and it is compared with the results corresponding to the existing structure of drives of knitting machines. At the same time, there is analysis and comparison of the consumption of electric power by the original and optimised systems.
\end{abstract}

\section{Keywords:}

Knitting machine, small-diameter cylinder, power input, coupling, drive, unit

\section{Introduction}

Among the most productive and most employed machines in the knitting industry there rank circular knitting machines. From the very beginning, the circular knitting machines have been developed in two variants, namely for the manufacture of hosiery products (the small-diameter ones) and for the manufacture of underwear, outerwear and special products (large-diameter ones). The present small-diameter knitting machines are in overwhelming majority equipped with one brushless servo motor, driving the needle cylinder, the dial and the cutting disk by means of mechanical transmissions. In an effort to make the production as economical as possible, there arise a number of problems related with dynamic behaviour of the machine [1]. Both in the past and at present, these machines are governed by relatively complicated mechanisms with one central drive and a large number of partial transmissions, due to which the efficiency of the output transmission drops down, in dependence on the type and quality of the transmission [2]. The drive systems employed at present do not utilise the individual assemblies realising the knitting process with maximum efficiency, with increased consumption of electric power as a consequence.

In [3] there has been proposed a new structure of the drive of small diameter knitting machines with the aim of simplifying the driving system, increasing the efficiency of the process, reducing the energy demand and improving dynamic characteristics of the driving sub-system. This article follows in the work described in [3], focusing on the proper system of numerically controlled servo drives, on the comparison of former and new driving systems and on the new opportunity of controlling the servo motors by means of advanced mathematical functions and their effect on real behaviour of the machine.

The original structure is based on a system of a single motor with mechanically intricate transmission system. This system must be able to provide for two modes of operation at least, when all the driving elements perform synchronous nonreversible rotation, or perform reverse swinging motion $270^{\circ}$ in both senses of rotation. For the mode of synchronous rotation is a necessity in order to secure the proper function of the machine, it is indispensable to satisfy the requirement following from the necessary high precision of adjustment of the mutual deviation of dial and the needle cylinder with tolerance $\pm 0.1 \mathrm{~mm}$ on the diameter $100 \mathrm{~mm}$, which corresponds to the slewing of the needle cylinder $3,5 \times 10^{-4}$ rad.

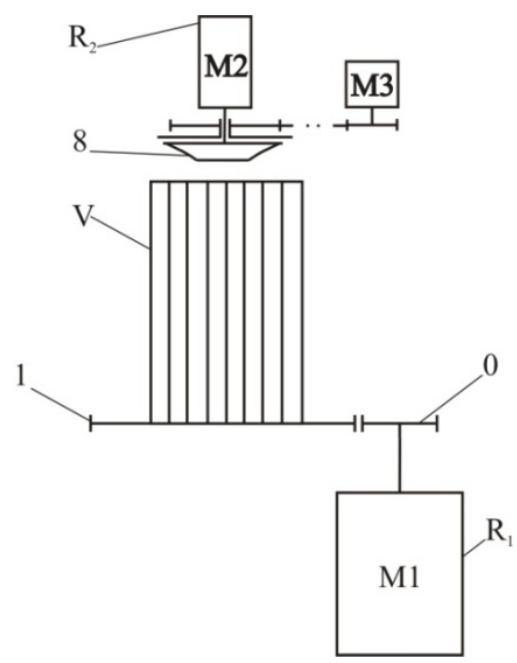

Figure 1. New system of drive of small diameter knitting machines, [3] 
The new structural concept (fig. 1) tries to eliminate the fixed mechanical coupling between the knitting cylinder (fig. 1 item V) and the main rib dial (fig.1, item 8) maximally [3]. The solution is shown schematically in figure 2; in addition to structural simplification, it brings in particular a reduction of the inertia moment of the kinematic chain, the possibility of independent operation of individual components (and consequently, saving of energy in case that during certain modes of operation, only some kinematic elements are engaged in the production actively), suppression of plays in the transmissions, and in particular, lower energy demand. Moreover, previous analyses also have shown advantages in comparison with the existing structural arrangement, in particular in the reduction of position deviation. Provided that a suitable controlled servo drive is employed, an optimised structure can enable achieving a reduction of the deviation in the level of several orders $[4,5]$.

The new solution of the drive offers the control of mutual position and velocity of the individual operating elements without mechanical linking, in a purely electronic manner. This is realised on the basis of evaluation of present positions of individual elements thanks to a highly precise electronic feedback control of the frequency converter by means of an implemented program in the master control module Advanced Position Control (APC). The links and transmissions among individual operating elements can be changed by mere alteration of the control program, without the necessity of mechanical interference in the machine construction. The said issues of substituting mechanical couplings with electronic ones have been discussed in the studies $[6,7]$.

By applying the function of a polynomial of 7 th degree and reduction rotating parts of the drive, the new structure provides reduced vibration and noise affecting an attendant of the machine and require less maintenance. As regards the textile goods are expected to increase productivity and product quality and decrease spoilage since vibration adversely affect mechanically fine knitting machine system.

\section{Electronic control of motions of the drives}

An experimental verification of characteristics of new structure of the drives of knitting machines has been realised on a testing equipment, the main components of which are two servo motors of the series CTM4, governed by frequency converters Emerson Control Techniques Digitax ST. The master control program governing the motion of operating elements and the mutual synchronisation has been realised on additional application module SM-Application. The time constant of the control loop of the system has been set up to $500 \mu \mathrm{s}$, which provides the sampling frequency of the control and measuring sub-systems $2 \mathrm{kHz}$. On this frequency, there have also been obtained the courses of the measured operating variables. The proper communication with the sensors and with the current loop of the converter has been adjusted to $250 \mu \mathrm{s}$. In the quality of input sensors, there have been employed 32-bit multi-turn sinus-cosine encoders with absolute sensing of the position and resolution of 16 bits per one revolution. The resolution of 65.536 increments per revolution provides the theoretical least magnitude of a measurable step of the motor $0.005^{\circ}$. This adjustment has also been used for obtaining the data which have been measured by recording the release values of encoders in the real time. The above-mentioned precision is not a decisive parameter for the reverse motion; however, it points out reliably the fact that these servo drives can be employed without any problem for the regime of synchronous rotation, where the position deviation between the needle cylinder and the dial constitutes the principal indicator of usability of the solution [5].

The testing equipment has consisted of two motors M1 Master and M2 - Slave. The Master drive governs the proper communication between converters, sets up the mode of operation and actuates the measuring process. Due to electronic communication, it is possible to generate any number of various operation regimes, may it be the selection of varied transmissions, varied velocities or the complex control function described below. The total quantity of regimes is limited by the finite program memory of the control module only, and it can reach tens or hundreds practically, depending on the implementation and intricacy.

Owing to these new possibilities, a motion function of higher degree has been created for the new structure of the machine. The purpose of this function is to secure an impact-free course of the motion during the reverse regime of the knitting machine, continuous even in the frame of higher derivatives. The selected polynomial of the $7^{\text {th }}$ degree [4] has been proposed so that it might secure a continuous course of acceleration of the reverse motion. In fig. 2 , the course of acceleration at the new driving dependence is compared with the original motion function, the acceleration of which has the form of linear function. The control of the motion is based on the principle of a virtual cam; therefore, the courses shown below have the axis $X$ represented as one revolution of the virtual cam. The first section represents the swing "forwards", the second section from $\pi$ to $2 \pi$ the reverse motion, which in ideal case is a perfect reflection of the motion forwards. The length of one period in the time area, taken over from the original variant of the machine, is $0.64 \mathrm{~s}$. Thanks to the new structure of electronically controlled drives, this value can be now altered easily by a program amendment according to the needs of the production technology.

In fig. 3, there is shown the deviation of measured slewing of the needle cylinder from the required course. Moreover, there is shown the deviation of the course of the measured velocity of the needle cylinder from the velocity required for one period of the reverse motion (fig. 4). In comparison with the mathematical model of the new structure of the drive [3], the actually measured values show a monitoring precision of the required course of the deviation lower by $25 \%$.

Of importance is also the comparison of operating variables of the original and optimised structures of small diameter knitting machines. The following diagrams show the courses of velocity and acceleration (figs. 5, 6) for the former structure with driving polynomial in the form of function of $3^{\text {rd }}$ order, and for the new structure with newly devised motion function in the form of a 


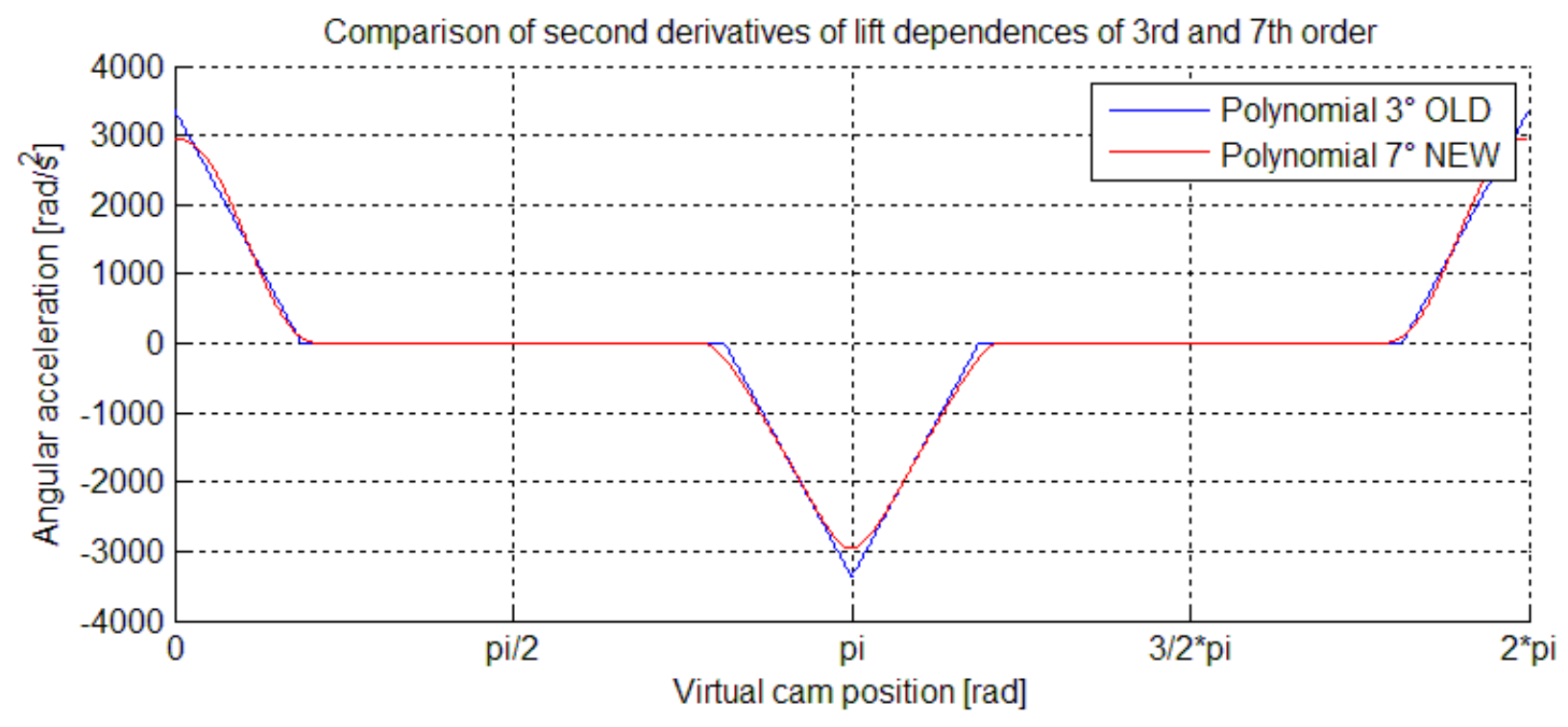

Figure 2. Comparison of second derivatives of the original and new polynomials

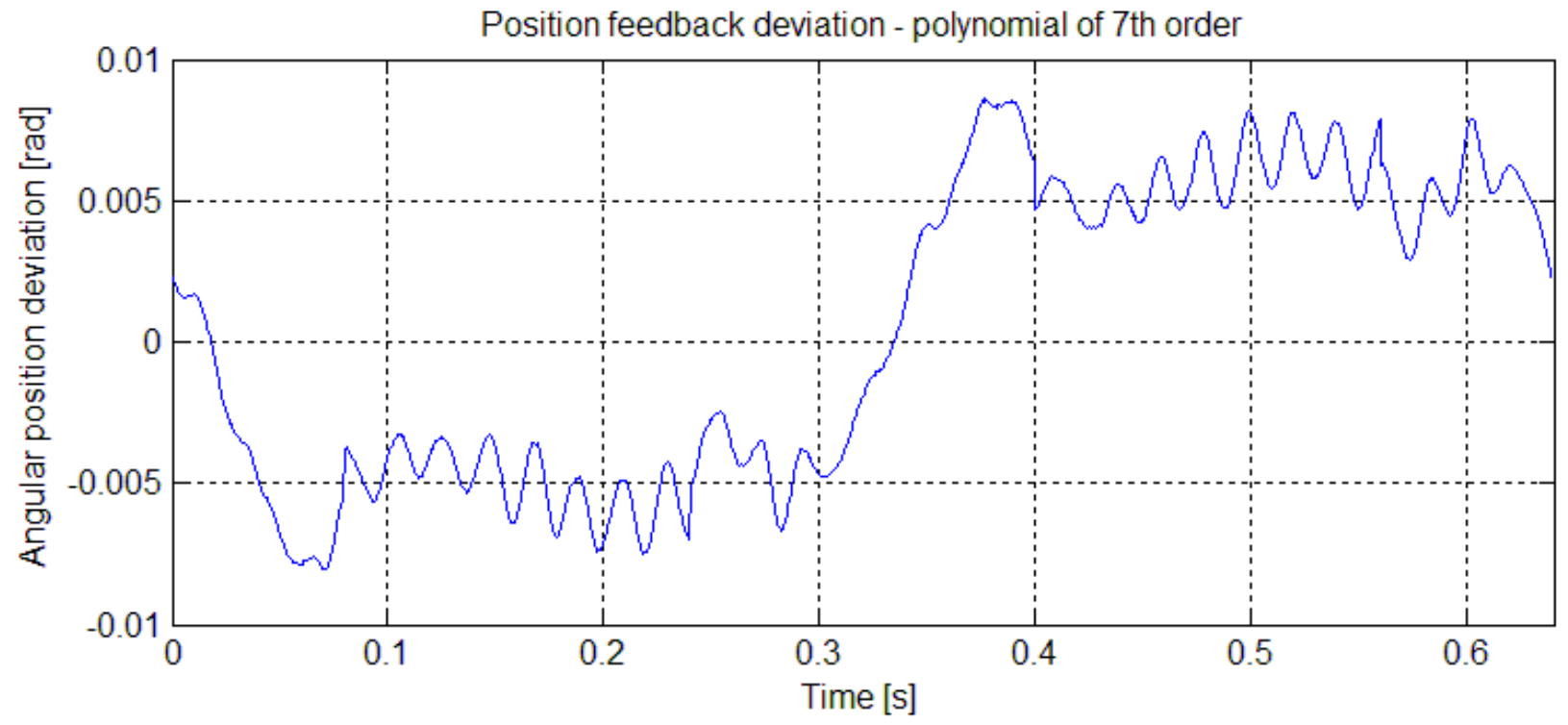

Figure 3. Deviation of the measured position from the required course

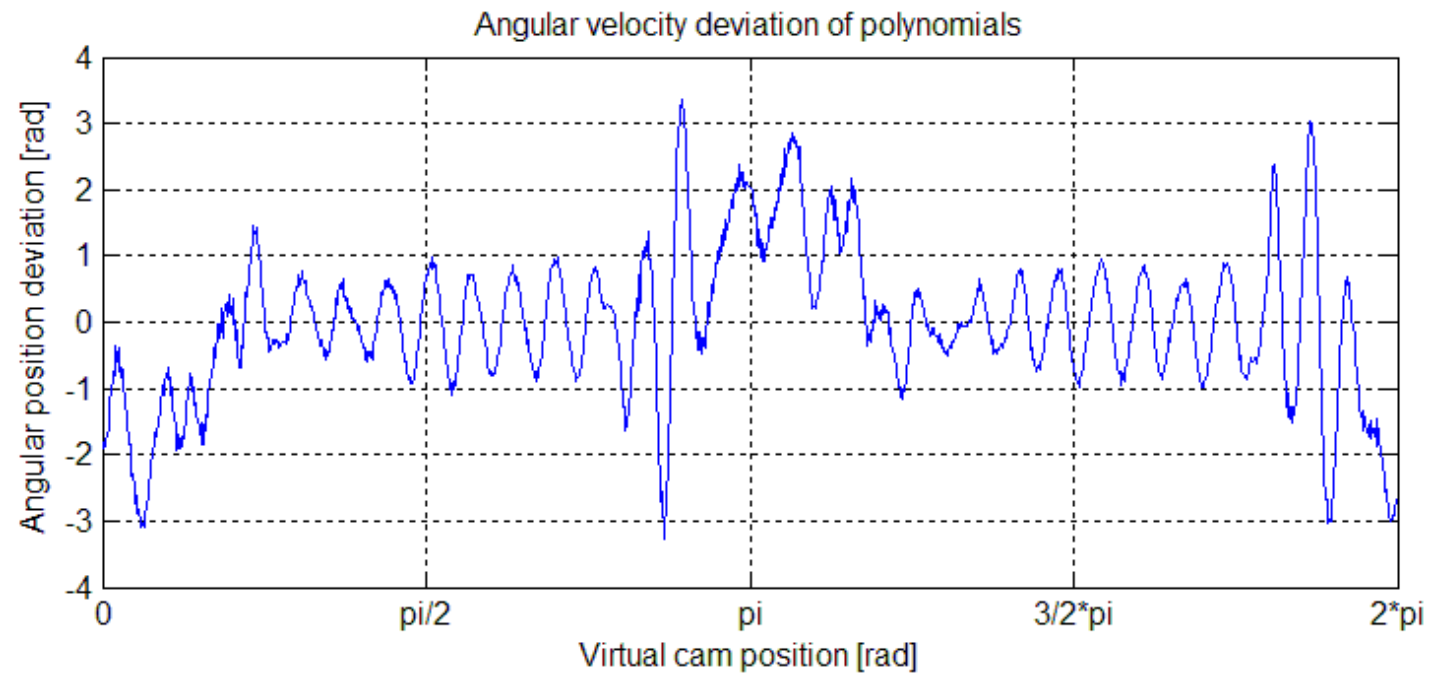

Figure 4. Deviation of the measured velocity from the required course 
polynomial of $7^{\text {th }}$ order $[4,5]$. For the sake of better clearness, the below shown diagrams are represented on the time axis in the way they have been measured. The biggest difference is notable concerning the acceleration in fig. 6; of an analogous character is also the course of the current of the motor Master in fig. 7. By the integration of given values there has been calculated that the consumption of electric power for the new structure (Polynomial of $7^{\text {th }}$ degree, New) represents $77 \%$ of the consumption of original structure of knitting machines. Henceforth, in the frame of one swinging period $23 \%$ of electric energy have been saved.

To verify the applicability of the optimised structure in the reverse mode and also in the mode of the synchronous rotation

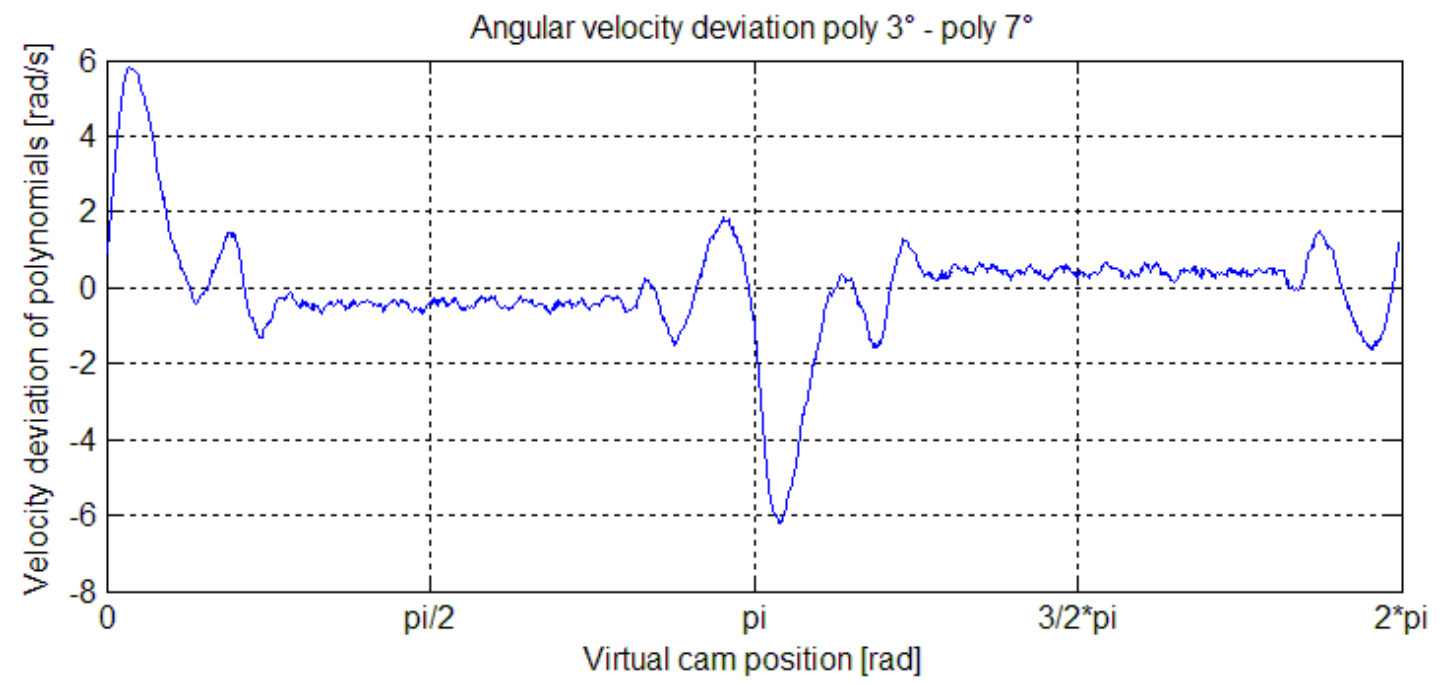

Figure 5. Difference of courses of velocity of the original and optimised structures of knitting machine

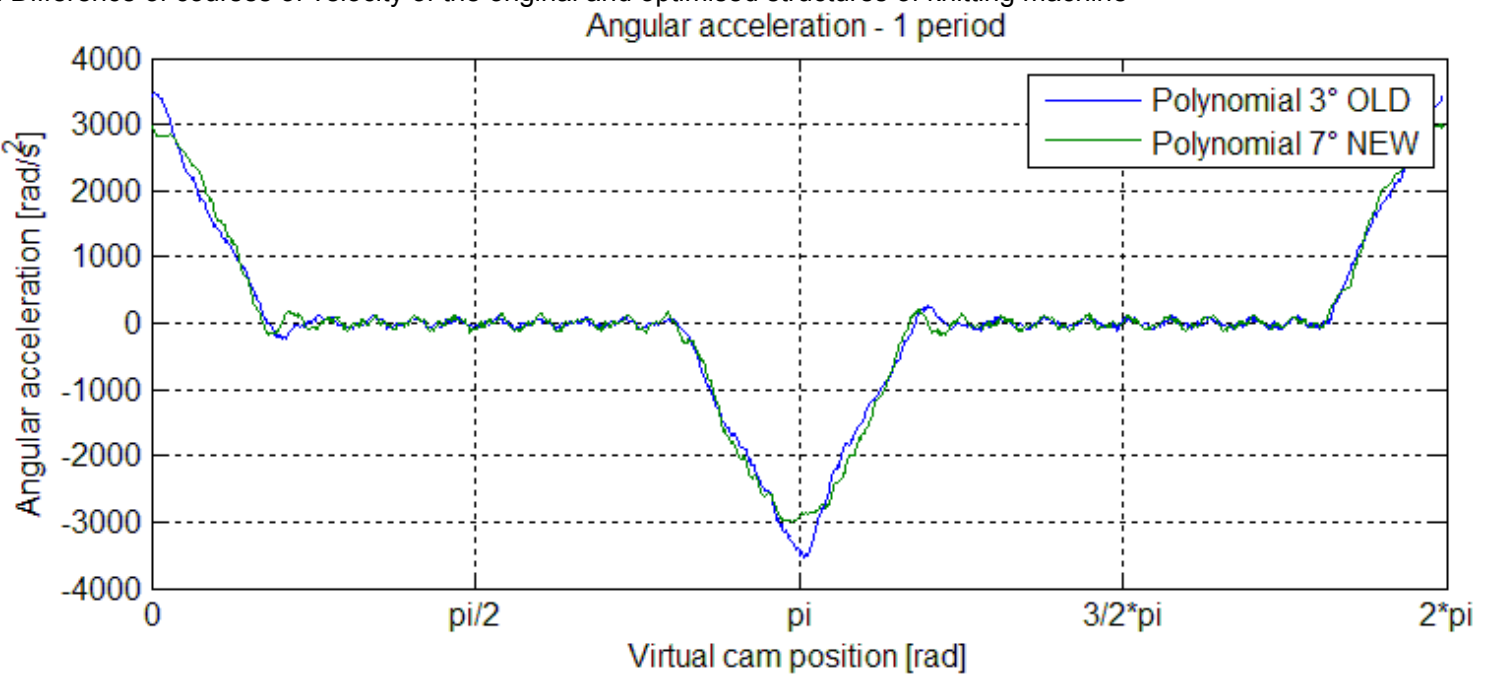

Figure 6. Comparison of the courses of acceleration of the original and optimised structures of knitting

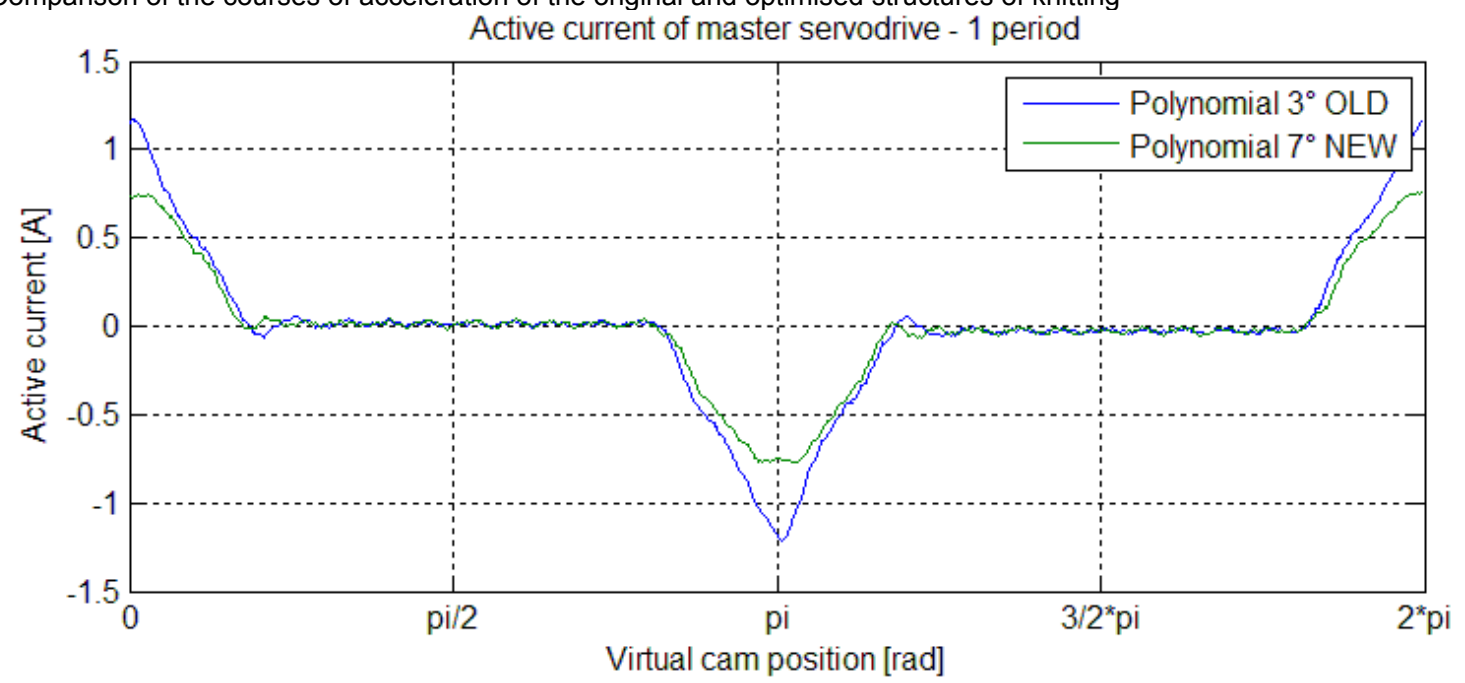

Figure 7. Comparison of the courses of active current of the drive Master of the original and optimised structures of knitting machine http://www.autexrj.com/ 


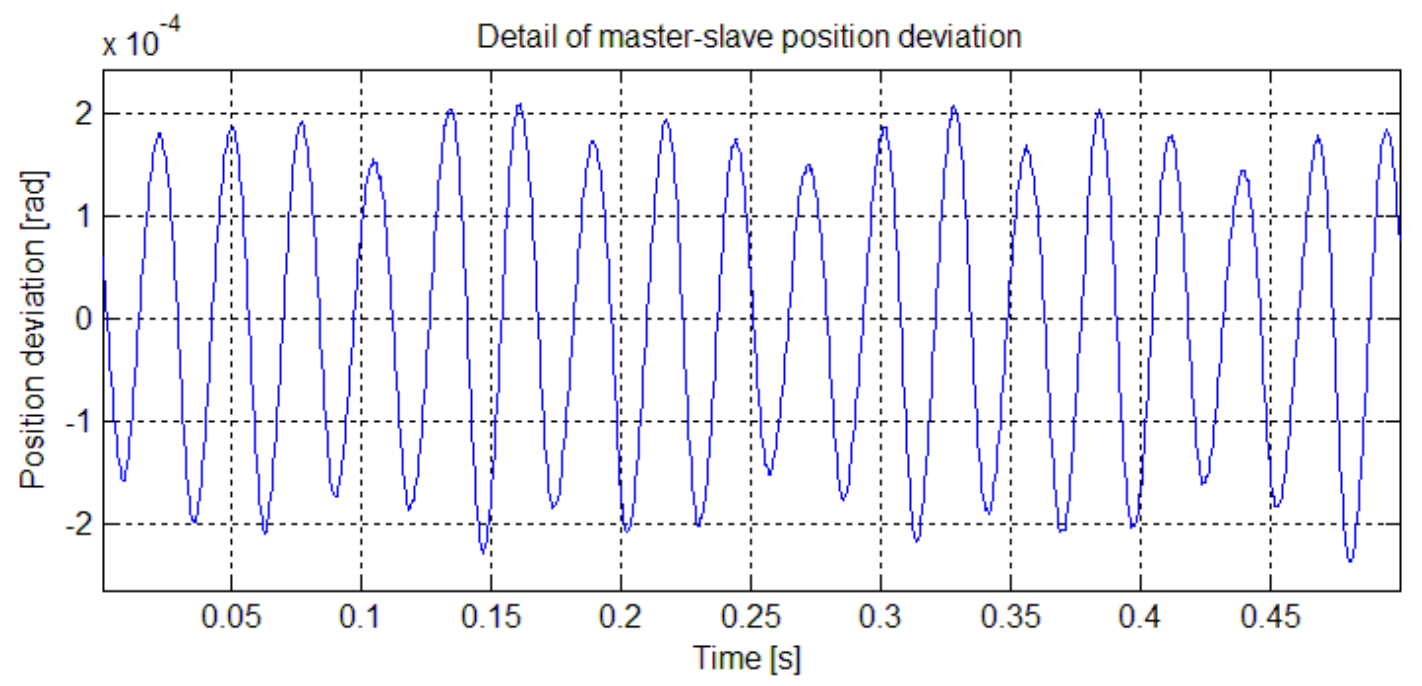

Figure 8. Deviation of the measured position between the cylinder and the dial (master and slave)

position deviation has been detected between the cylinder and the dial (fig. 8). The ascertained deviation points to use reliable solution with approximately $40 \%$ safety margin with respect to the peak value see introduction.

\section{CONCLUSIONS}

The results presented in the article utilise the optimised structure of the drives of small diameter knitting machines. For the verification of this structure there has been devised an experimental equipment with the corresponding moments of inertia of the load with respect to the types of servo drives. This structure represents a significant structural simplification of the system of drives of knitting machines utilising a pair of electronically controlled servo drives. Thanks to this simplification, the loading has been reduced by the reduction of the mass, the dynamic loading has been reduced and the efficiency of the technological process has been increased. Together with the above-mentioned principal benefits, it is also possible to expect further associated benefits, such as longer service life or lower noise level during the operation of the equipment.

Thanks to the system of electronically controlled drives, it is possible - by implementation of an electronic gear box or a virtual cam - to alter and change the operation of the equipment by a mere change of program or parameters. It is also possible to make use of the advanced method of motion control, demonstrated on the example of the proposed motion polynomial of $7^{\text {th }}$ degree, which (see figures 3 and 9) allows reaching comparable courses of the velocity and position at lower acceleration peaks, and a moderate reduction of the level of vibrations, in particular during transitions among motion intervals of the motion function.

A comparison of courses of the acceleration in fig. 9 has also shown, among other things, that the employed servo drives will 'soften' possible discontinuities in higher derivatives; a cardinal importance of the polynomial of higher degree for the impactfree course has therefore not been proven unequivocally in this respect for an optimised structure. However, thanks to this polynomial it has been possible to reduce the peak loads of the drive, as well as the total power consumption, which with the new structure employing polynomial driving function has achieved a $23 \%$ reduction in comparison with original values. From the overall results it is evident that the present drives are able to secure both the starting-ups and run-outs by means of a polynomial of $7^{\text {th }}$ degree with the above mentioned advantages.

\section{ACKNOWLEDGEMENTS}

The paper has been elaborated with the financial support of TUL in the framework of specific university research competition.

\section{References}

[1] Skřivánek, J., Bílek, M., Kulichová, Š.: Mathematical model of the frame of small-diameter knitting machine, Sborník prednášok 11. medzinádnej vedeckej konferencie „TRANSFER 2009“, str. 48, Trenčianska univerzita $\checkmark$ Trenčine, Trenčín 2009

[2] Skrivánek, J., Bílek, M.: Analysis of dynamic model of the drive of small diameter knitting machines ange 18.1, Acc Journal XVII 2011, Liberec, 2011. ISSN 1803-9782

[3] Skřivánek, J., Bílek, M.: New structure of the drive of smalldiameter knitting machines, AUTEX Research Journal, Vol. 12, No1, March 2012 @ AUTEX,ISSN 1470-9589

[4] Skřivánek, J., Bílek, M.: Optimization of lift dependence of the new structure of small-diameter knitting machines, ACC JOURNAL XVIII, Liberec, 2012, ISSN 1803-9782.

[5] Skrivánek, J., Bílek, M.: Application of the impact-free lift dependence in small-diameter knitting machines, XI. International Conference on the Theory of Machines and Mechanisms, pp.: 445-450, September 4-6. 2012, Liberec, Czech Republic, ISBN 978-94-007-5124-8

[6] Vaclavik, M., Jirasko, P., "Research and Application of Displacement Laws of Electronic Cams," Proceedings of the 13th IFToMM World Congress, Besancon, France, June 18-21, 2007

[7] Tesar, D., "Intelligent Mechanical Systems," Plenary Paper, Proceedings of the 11th IFTOMM World Congress in Mechanism and Machine Science, Tianjin, China, April 1-4, 2004. 